\title{
ЗАКОНОМЕРНОСТИ ДИНАМИКИ РОСТА ЛИСТЬЕВ ДЕРЕВА
}

\author{
А.И. Кудряшова \\ Поволжский государственный технологический университет, \\ г.Йошкар-Ола

\section{THE WAY TO MEASURE GROWTH DYNAMICS OF TREE LEAVES}

\author{
A.I. Kudryashova \\ Volga State University of Technology, Yoshkar-Ola
}

\begin{abstract}
Аннотация. Рассмотрены примеры изменения во времени на разных этапах вегетации по четырем параметрам (длины и ширины листа, периметра и площади) группы листьев, а также показано повышение точности измерений динамики этих параметров учетных листьев во времени, начиная от начала распускания почек.

Abstract.Examples of changes over time at different stages of the growing season by four parameters (sheet length and width, perimeter, and area) of the group leaves, and also shows the improved accuracy of the measurements of the dynamics of these parameters account leaves in time, starting from the beginning of Bud burst.
\end{abstract}

Ключевые слова: лист дерева, параметры, динамика, закономерности.

Keywords: tree, parameters, dynamics, patterns.

Можно моделировать данные по каждому учетному листу [1].

Однако мы не знаем влияющие факторы среди популяции из 10 листьев, выбранных как учетные в локальной зоне на поверхности кроны липы. Поэтому будем искать по всем 10 учетным листьям среднестатистическую линию поведения у всех 10 учетных листьев.

Длина листа изменяется (рис. 1) по формуле

$$
\begin{aligned}
& a_{t}=10,85422 t^{0,65795} \exp \left(-0,00019680 t^{1,73403}\right)+A \cos (\pi t / p-1,62013), \\
& A=4,75240 \cdot 10^{-33} t^{20,44582} \exp \left(-0,063164 t^{1,19166}\right), \\
& p=2,99774+0,10895 t^{0,94969}
\end{aligned}
$$

где $a_{t}$ - переменная во времени среднестатистическая длина листьев, мм, $t$ - время вегетации с начала распускания листьев, сутки, $A$ - амплитуда (половина) колебательного возмущения длины листьев в динамике роста популяции из 10 листьев, мм, $p$ - полупериод колебания длины учетных листьев, сутки. 
Первый член формулы (1) является биотехническим законом, а половина амплитуды у второго члена в виде волновой функции также является биотехническим законом. При этом второй член имеет перед собой положительный знак, что указывает на позитивное влияние волнового возмущения на рост длины листьев. Тем самым становится понятным, что волновая адаптация растений к окружающей сред является основным механизмом их роста и развития.

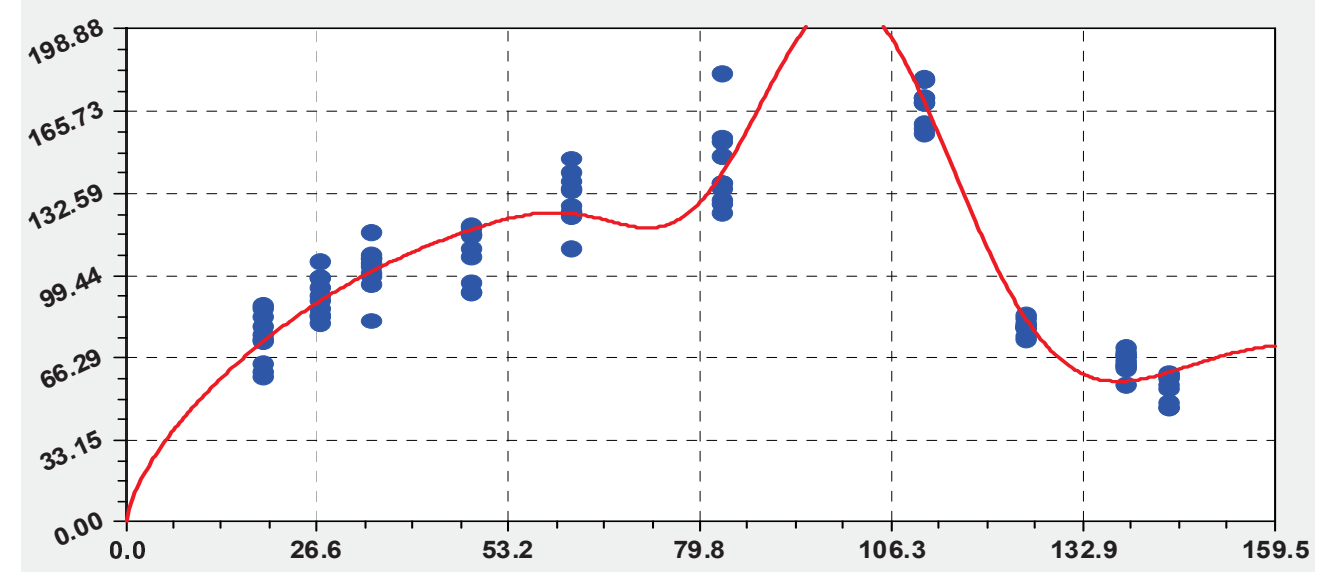

Рисунок 1 - График среднестатистической закономерности динамики длины листьев липь

При этом в начале вегетации при распускании почек на дату 02.05.2014 период колебания был равен $2 \times 2,99774 \approx 6$ суток, а начало колебания произошло чуть позже даты 02.05.2014 (примерно 3-5 суток). Затем, по мере взросления организма листа, этот период возрастает, то есть колебательная адаптация успокаивается. Адекватность формулы (1) по коэффициенту корреляции равен 0,9765 и этот уровень тесноты связи является сверхсильным (допустимый коэффициент корреляции более 0,95 ) факторным связям.

Ширина листа изменяется (рис. 2) по аналогичной по конструкции двухчленной формуле

$$
\begin{aligned}
& b_{t}=9,10233 t^{0,74348} \exp \left(-0,00026140 t^{1,74429}\right)+A \cos (\pi t / p+1,86598), \\
& A=1,00341 \cdot 10^{-22} t^{13,54328} \exp \left(-0,0025789 t^{1,72624}\right), \\
& p=192,24495-29,76665 t^{0,30703} .
\end{aligned}
$$

Хотя конструкция формулы одинакова, но характер поведения ширины у популяции 10 учетных листьев иной.

Коэффициент корреляции 0,9400 меньше, чем у формулы динамики длины листа, и относит формулу (2) к сильнейшим (более 0,9$)$ связям. При этом коренным образом иной полупериод колебания. При этом начало колебания ширины листа намного раньше срока распускания почек (повидимому, рост ширины листа заложен генетически намного раньше даже начала сокодвижения). На дату 02.05.2014 период колебания равен 
$2 \times 192,24495 \approx 384$ суток. Это больше годичного периода обращения Земли вокруг самого себя в 365 суток.

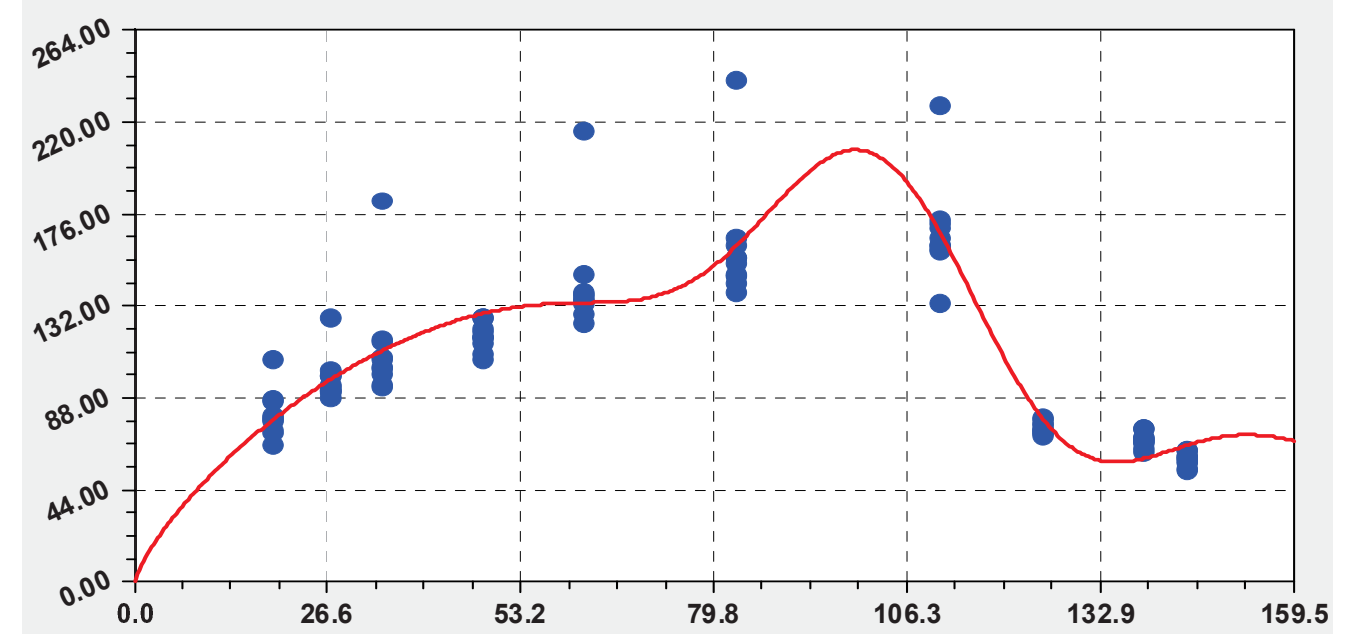

Рисунок 2 - График среднестатистической закономерностидинамики ширинь листьев липь

Отрицательный знак в формуле полупериода показывает, что фенотипической волновой адаптацией листья липы быстро убавляют значение периода колебания. Это апостериорный факт показывает, что листья липы о ширине как бы быстро «приземляются» и, по-видимому, сброс листвы связан именно с динамикой ширины листьев липы.

Для длины и ширины листа рекомендуется обобщенная формула

$$
\begin{aligned}
& a_{t} \vee b_{t}=a_{1} t^{a_{2}} \exp \left(-a_{3} t^{a_{4}}\right)+A \cos \left(\pi t / p \mp a_{12}\right), \\
& A=a_{5} t^{a_{6}} \exp \left(-a_{7} t^{a_{8}}\right), p=a_{9} \pm a_{10} t^{a_{11}},
\end{aligned}
$$

где $a_{t}, b_{t}$ - переменные во времени среднестатистические длина или ширина у популяции из не менее 10 учетных листьев, мм, $\vee$ - знак логических отношений «или», $t$ - время вегетации с начала распускания листьев, сутки, $A$ - амплитуда (половина) колебательного возмущения длины или ширины листьев в динамике роста популяции из не менее 10 листьев, мм, $p$ - полупериод колебания длины или ширины у не менее 10 учетных листьев, сутки, $a_{1} \ldots a_{12}$ - параметры модели (3), получающие числовые значения после статистического моделирования идентификацией модели (3) по данным измерений длины или ширины у не менее 10 учетных листьев, при этом происходит чередование знаков: $+a_{10},-a_{12}$ принимают для закономерности динамики среднестатистической длины $a_{t}$ у популяции из не менее 10 учетных листьев; $-a_{10},+a_{12}$ принимают для закономерности динамики среднестатистической ширины $b_{t}$ у популяции из не менее 10 учетных листьев.

Периметр листа $P_{t}$ изменяется (рис. 3) по формуле 


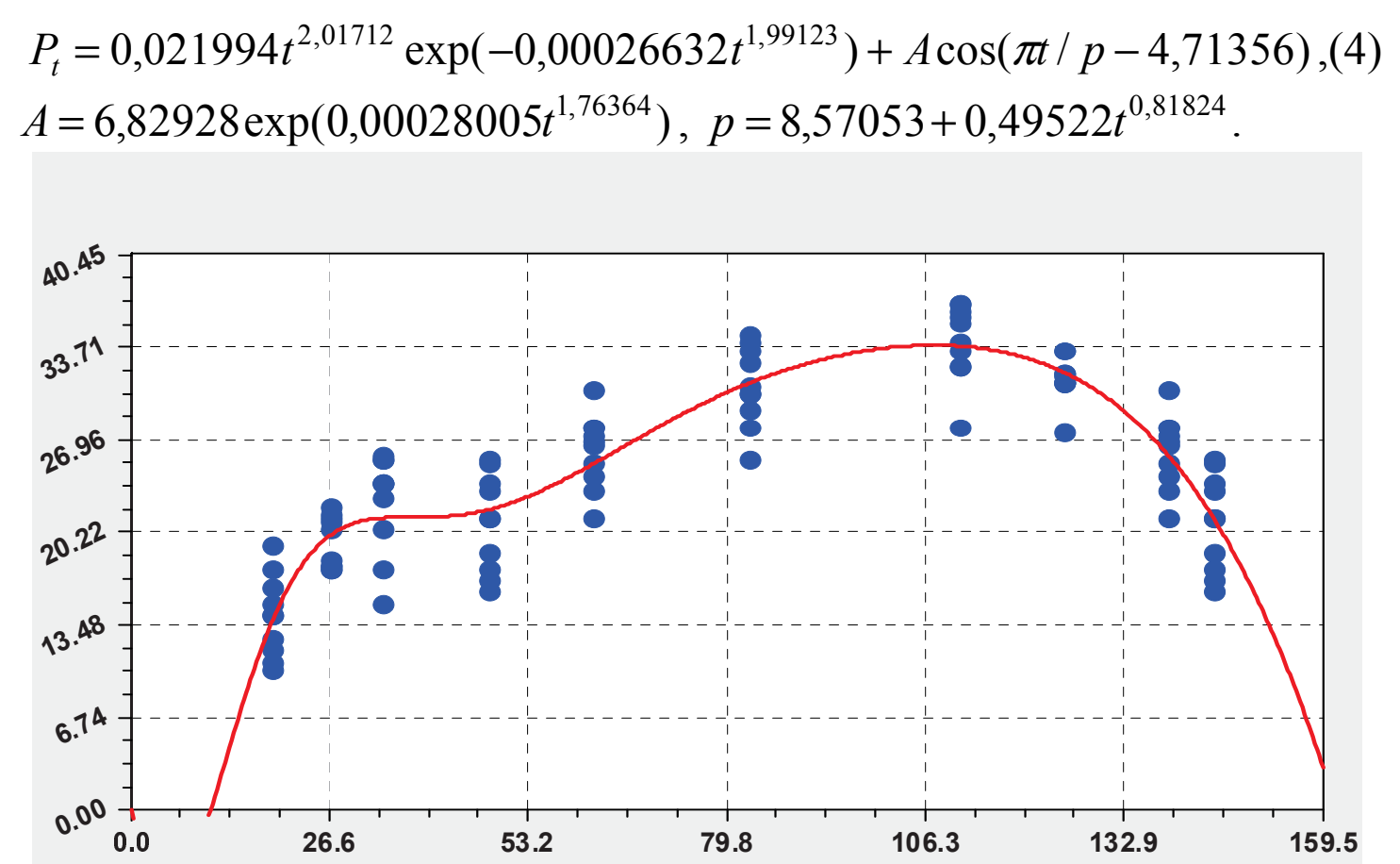

Рисунок 3 - График среднестатистической закономерности динамики периметра листьев липь

Адекватность формулы (4) по коэффициенту корреляции равен 0,9585 и этот уровень тесноты связи является сверхсильным (допустимый коэффициент корреляции более 0,95 ) факторным связям.

Начало волнения периметра происходит раньше 02.05.2014 (знак минус перед сдвигом волны). При этом амплитуда колебания изменяется со временем по закону экспоненциального роста, начиная от даты распускания почек при $2 \times 6,82928 \approx 13,7$ см. Затем амплитуда колебания возрастает и такое возмущение, по-видимому, приводит к превышению допустимой амплитуды колебательного возмущения периметра и затем к отторжению листа от веточки.

В момент распускания почек период колебания равен $2 \times 8,57053 \approx$ 17,2 суток. Затем колебание успокаивается. Таким образом, для периметра характерно рост амплитуды и рост периода колебания.

Площадь листа $S_{t}$ изменяется (рис. 4 ) по формуле

$$
\begin{gathered}
S_{t}=0,014161 t^{2,29339} \exp \left(-0,024747 t^{0,99991}\right)+A \cos (\pi t / p-1,57511), \\
A=4,46628 \exp \left(0,00011616 t^{1,88117}\right), p=-9,37122+32,12674 t^{0,10813} .
\end{gathered}
$$

Адекватность формулы (5) по коэффициенту корреляции равен 0,9838 и этот уровень тесноты связи является наибольшим из четырех параметров ученых листьев и при этом является сверхсильным (допустимый коэффициент корреляции более 0,95$)$ факторным связям. 


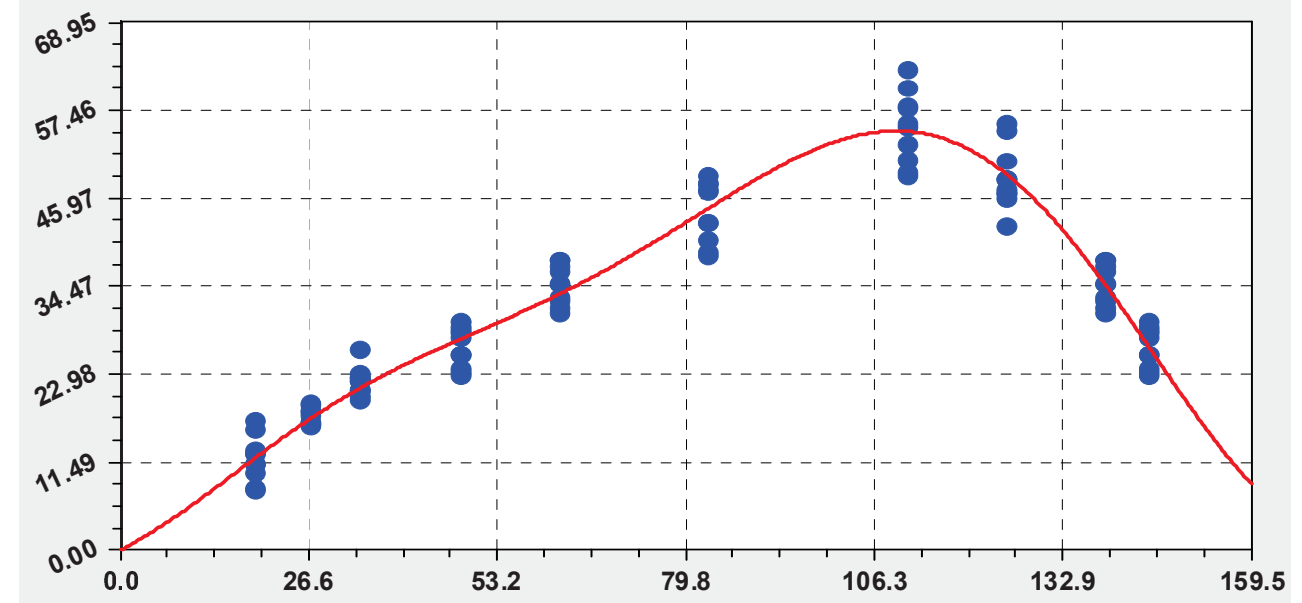

Рисунок 4 - График среднестатистической закономерности динамики площзади листьев липь

Амплитуда колебания на 02.05.2014 равна $2 \times 4,46628 \approx 8,93 \mathrm{~cm}^{2}$, и это намного больше поперечного сечения самой почки. С дальнейшим ростом учтенные листья резко наращивают амплитуду колебания. Повидимому, наступает момент превышения амплитудой допустимого предала. При этом периметр и площадь действуют одинаковым образом.

Для периметра и площади листа рекомендуется обобщенная формула

$$
\begin{aligned}
& P_{t} \vee S_{t}=a_{1} t^{a_{2}} \exp \left(-a_{3} t^{a_{4}}\right)+A \cos \left(\pi t / p-a_{12}\right), \\
& A=a_{5} t^{a_{6}} \exp \left(-a_{7} t^{a_{8}}\right), p=a_{9}+a_{10} t^{a_{11}},
\end{aligned}
$$

где $P_{t}, S_{t}$ - переменные во времени среднестатистические периметр (см) или площадь $\left(\mathrm{cm}^{2}\right)$ у популяции из не менее 10 учетных листьев, $\checkmark$ - знак логических отношений «или», $t$ - время вегетации с начала распускания листьев, сутки, $A$ - амплитуда (половина) колебательного возмущения периметра (см) или площади $\left(\mathrm{cm}^{2}\right)$ в динамике среднестатистического роста популяции из не менее 10 учетных листьев, $p$ - полупериод колебательного возмущения при адаптации к внешним воздействиям периметра или площади учетных листьев, сутки, $a_{1} \ldots a_{12}$ - параметры модели (6), получающие числовые значения после статистического моделирования идентификацией модели (6) по данным измерений периметра или площади у не менее 10 учетных листьев.

По отношению к динамике параметров каждого из 10 листьев липы общая формула (3) оказалась неустойчивой, а обобщенная формула (6) для описания динамики периметра (табл. 5, рис. 5) и площади (табл. 6, рис. 6) оказалась высоко устойчивой.

Запишем оба члена у каждой модели (4) и (5) в виде вейвлет-сигнала, исходящего от каждого учетного листа о своем поведении. 
Волновое уравнение является асимметричным вейвлетом вида

$$
\begin{array}{r}
y_{i}=A_{i} \cos \left(\pi x / p_{i}-a_{8 i}\right), \\
A_{i}=a_{1 i} x^{a_{2 i}} \exp \left(-a_{3 i} x^{a_{4 i}}\right), p_{i}=a_{5 i}+a_{6 i} x^{a_{7 i}},
\end{array}
$$

где $A_{i}$ - амплитуда (половина) вейвлета, $p_{i}$ - полупериод колебания.

По формуле (7) с двумя фундаментальными физическими постояннымие (число Непера или число времени) и $\pi$ (число Архимеда или число пространства) образуется изнутри изучаемого явления и/или процесса квантованный вейвлет-сигнал. Понятие вейвлет-сигнала позволяет абстрагироваться от физического смысла самих рядов (в общем случае не только динамических) и рассматривать их аддитивное разложение.

Для периметра у 10 учетных листьев параметры вейвлет-сигналов даны в таблице 1, а соответствующие графики приведены на рисунке 5. Во всех моделях коэффициент корреляции, из-за превышения количества параметров модели 13 над количеством наблюдений 11, равен 1,0000.

Все восемь параметров, кроме сдвига волны $a_{8}$, имеют значительный интервал изменения своих значений. Этот факт указывает на высокую чувствительность предлагаемого способа и н практическую возможность изучения влияния разных факторов на динамику физических параметров у одного учетного листа липы и других деревьев.

Таблица 1

Параметры модели $P_{t i}=f(t)$ динамики периметра учетного листа липы

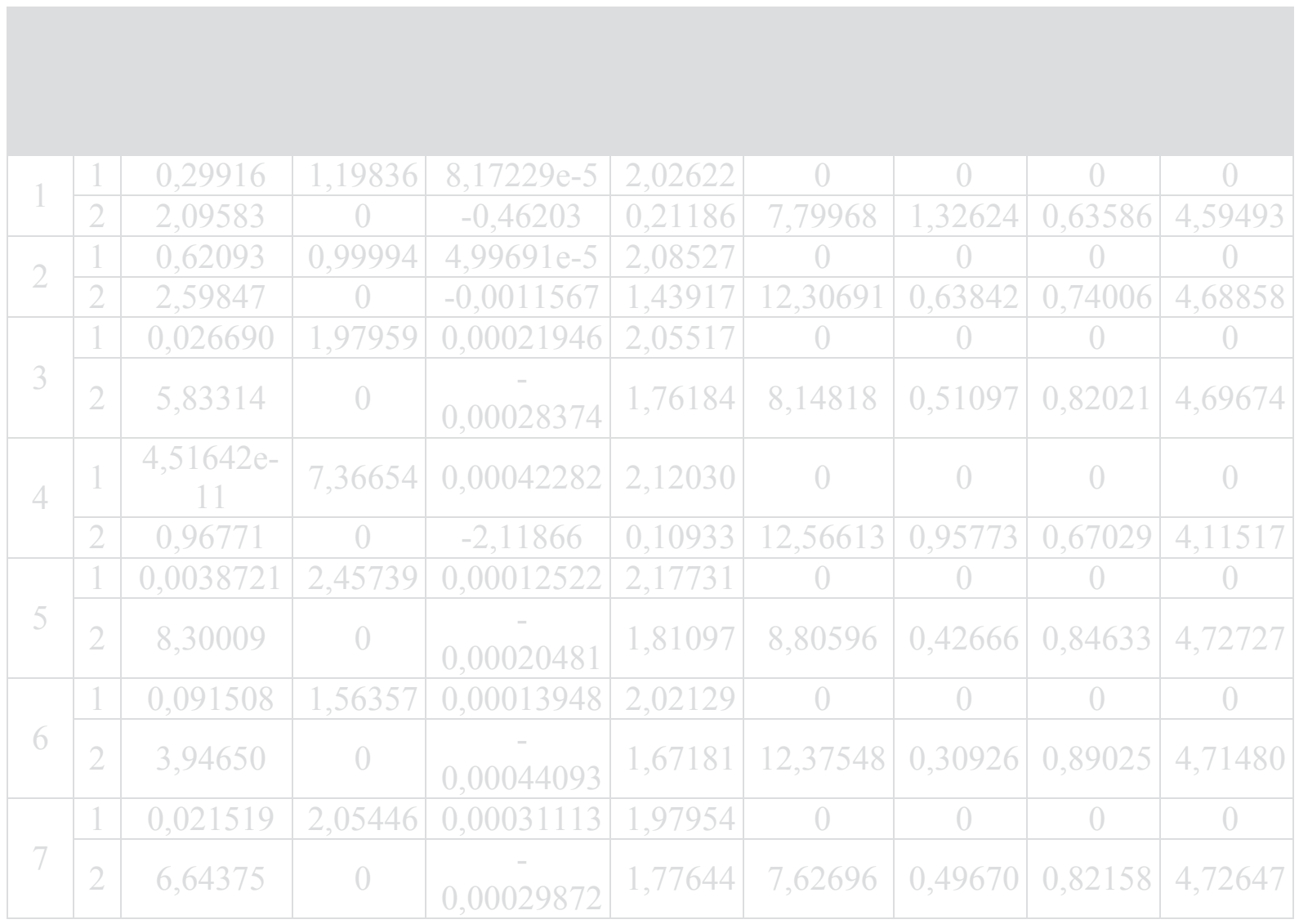



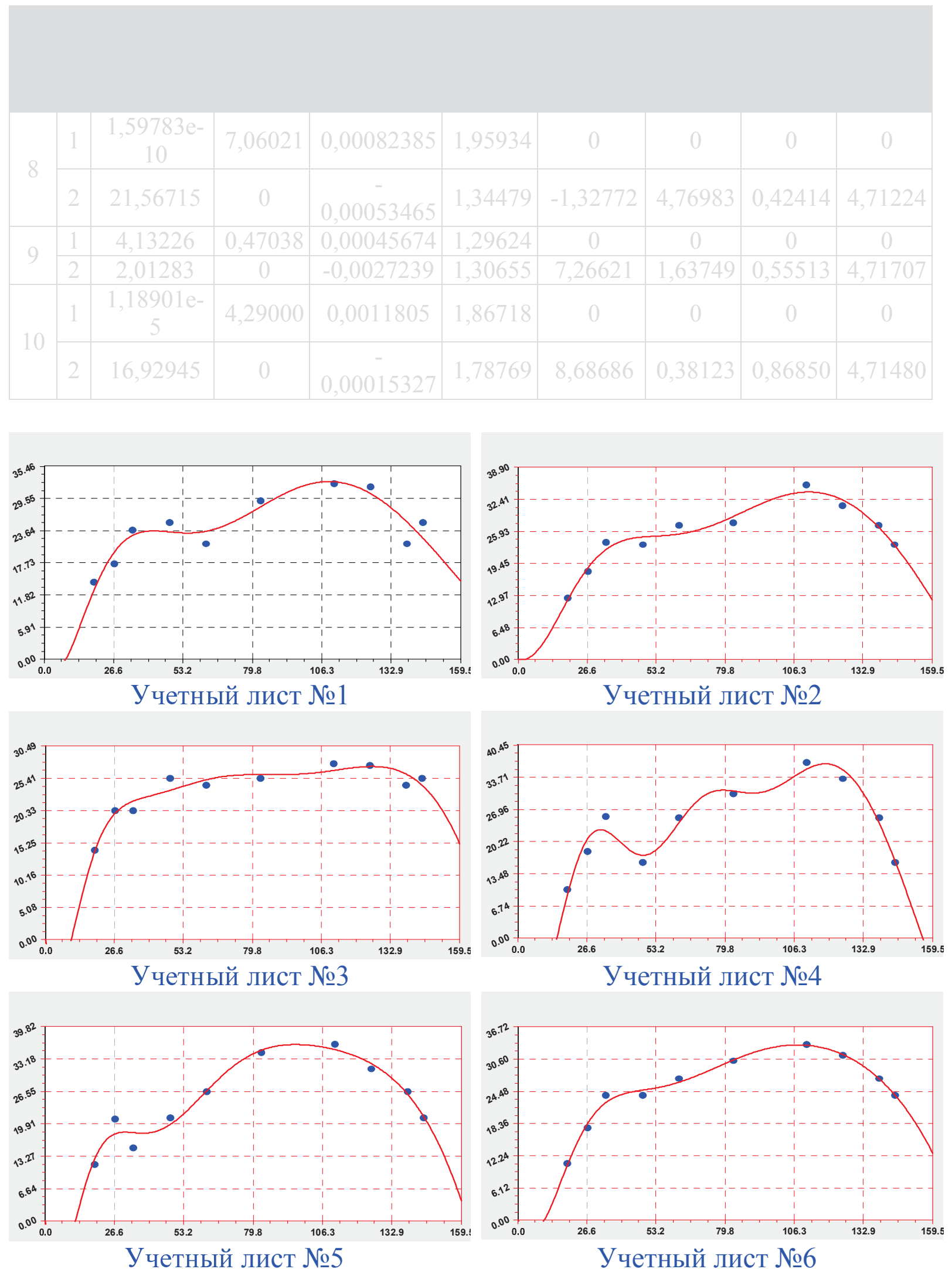

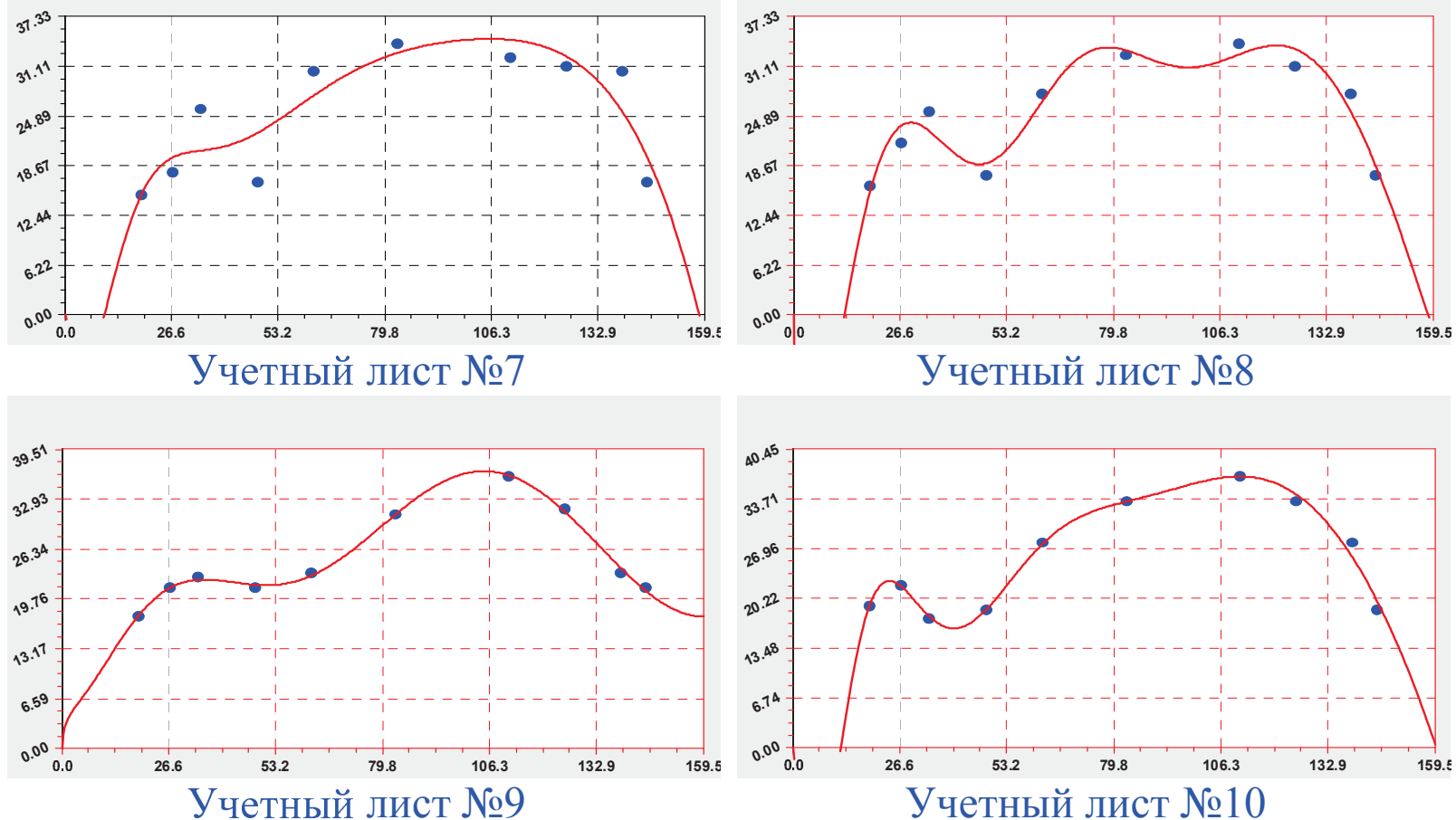

Рисунок 5 - Графики динамики периметра каждого учетного листа из группь из 10 учетных листьев на одной локальной зоне поверхности кроны липы

Для площади у популяции из 10 учетных листьев параметры вейвлет-сигналов у каждого учетного листа даны в таблице 6, а соответствующие графики приведены на рисунке 6.

Во всех моделях коэффициент корреляции, из-за превышения количества параметров модели 13 над количеством наблюдений 11, равен 1,0000 .

Из 10 учетных листьев только у листа №2 имеется отрицательный полупериод в начале распускания почек. Интервал изменения полупериода $a_{5}$ находится в пределах от $-3,57412$ до 21,47660 суток.

Преимуществом предлагаемого способа является техническая простота исполнения, так как из оборудования требуется только изготовить даже самому прозрачную палетку, например из листового оргстекла, а сотовый телефон с функцией фотографирования ныне очень распространен и имеется почти у каждого студента или школьника.
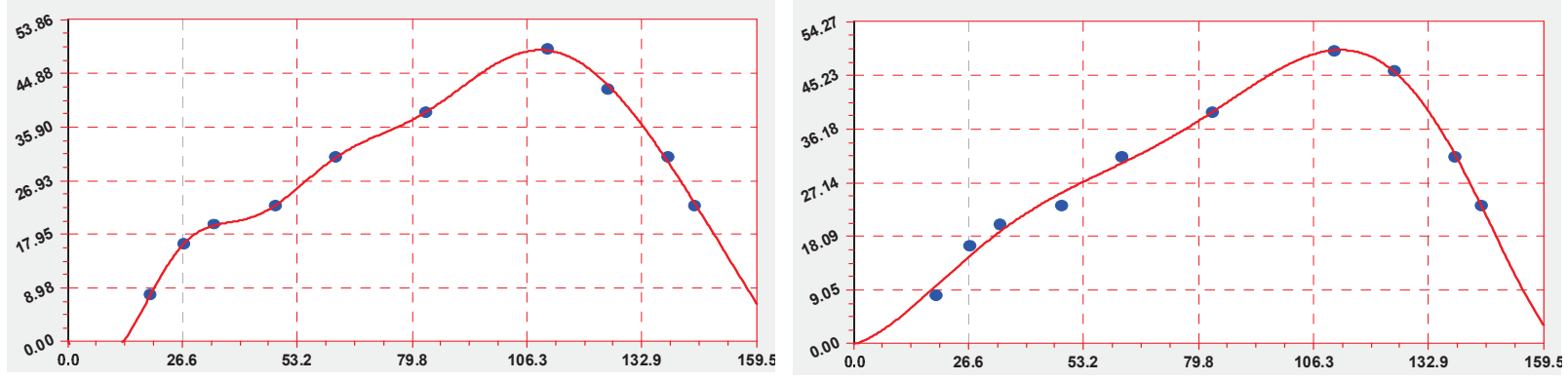
Учетный лист №1
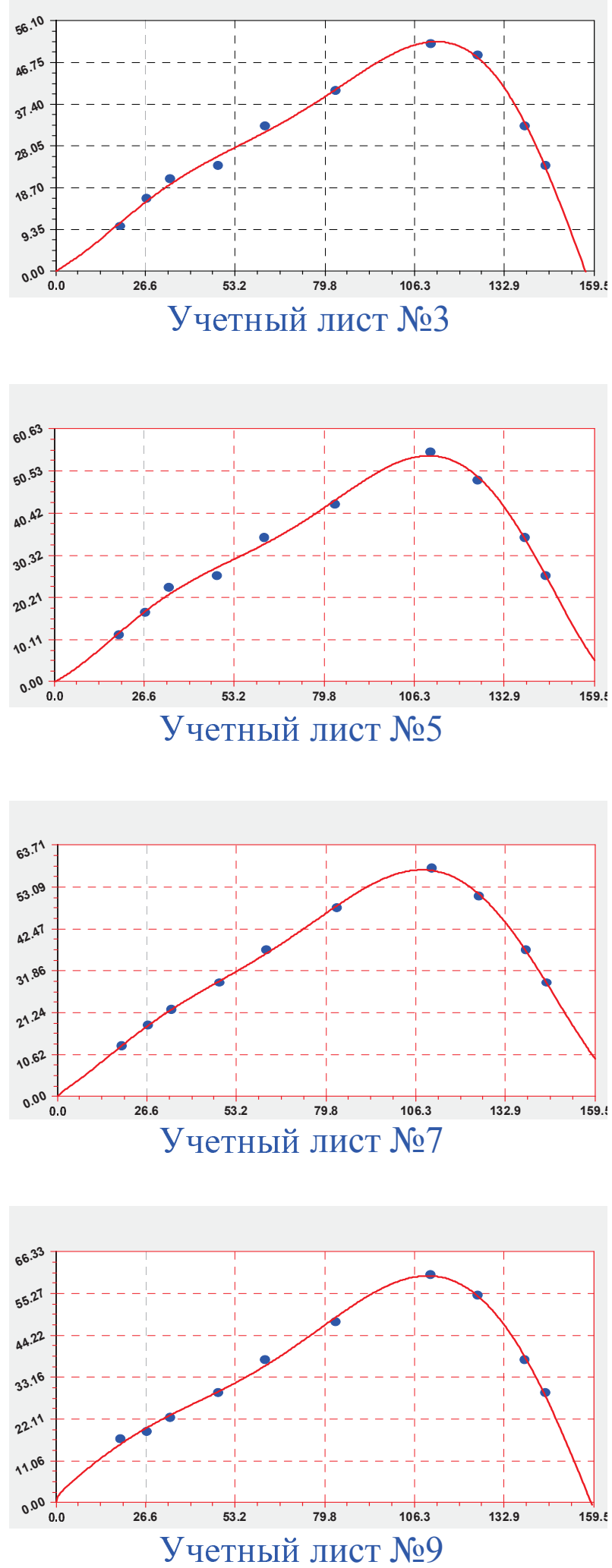

Учетный лист №2
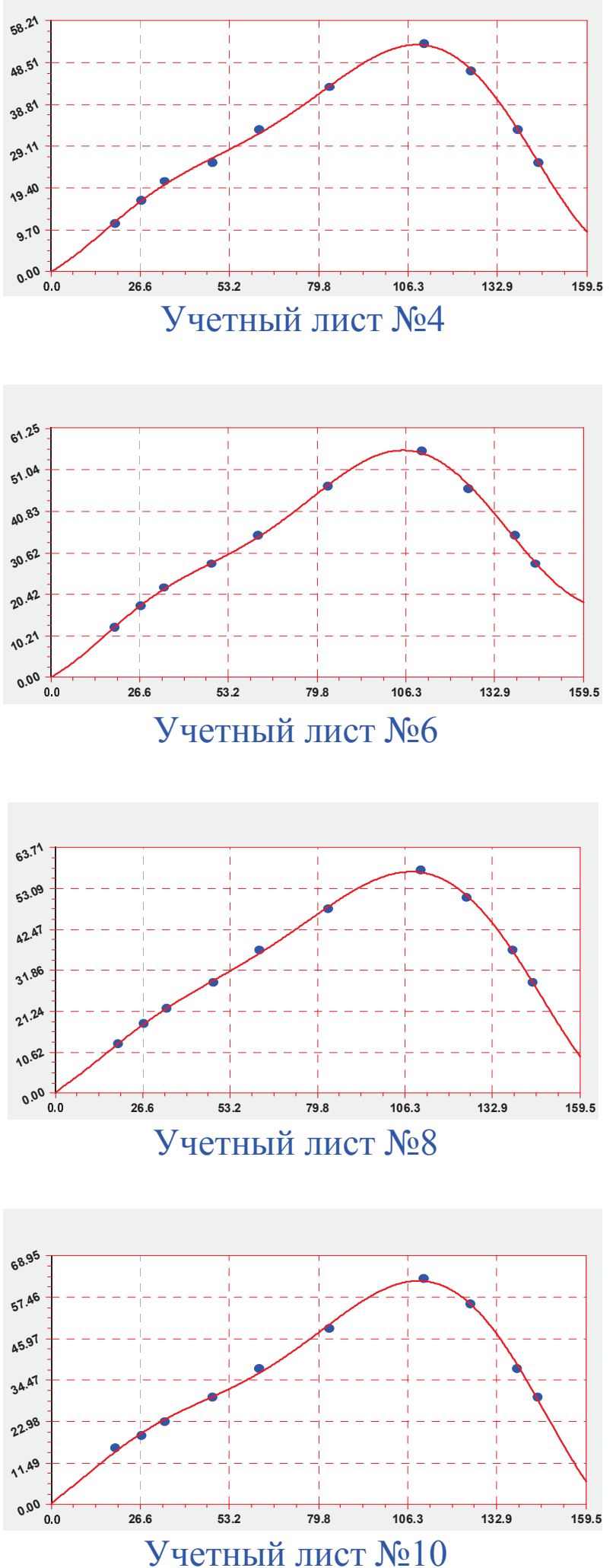

Рисунок 6 - Приведень графики динамики площади каждого учетного листа из группы из 10 учетных листьев на одной локальной зоне поверхности кроныл липь 
Таблица 2

Параметры модели $S_{t i}=f(t)$ динамики площади учетного листа липы

\begin{tabular}{|c|c|c|c|c|c|c|c|c|c|}
\hline & 1 & $8,23891 \mathrm{e}-10$ & 6,96580 & 0,0015199 & 1,89770 & 0 & 0 & 0 & 0 \\
\hline 1 & 2 & 0,0015897 & 0 & $-6,64398$ & 0,093399 & 21,47660 & 0,016381 & & 3,39927 \\
\hline \multirow{2}{*}{2} & 1 & 0,016622 & 2,20218 & 0,026019 & 0,97475 & & 0 & 0 & 0 \\
\hline & 2 & 2,77719 & 0 & $-0,00011788$ & 1,94716 & $-3,57412$ & 32,42048 & 0,080772 & 1,65910 \\
\hline \multirow{2}{*}{3} & 1 & 0,014671 & 2,26501 & 0,024966 & 0,99791 & & 0 & 0 & 0 \\
\hline & 2 & 3,63741 & 0 & $-8,21493 e-5$ & 2,01716 & 12,69603 & 31,79681 & 0,12448 & $-1,59203$ \\
\hline \multirow{2}{*}{4} & 1 & 0,013619 & 2,28764 & 0,024640 & 0,99817 & & 0 & 0 & 0 \\
\hline & 2 & 4,29291 & 0 & $-8,36215 e-5$ & 1,94321 & 8,95098 & 32,12027 & 0,10523 & 1,59110 \\
\hline \multirow{2}{*}{5} & 1 & 0,013879 & 2,29056 & 0,024695 & 0,99889 & & 0 & 0 & 0 \\
\hline & 2 & 4,14532 & 0 & $-9,49670 e-5$ & 1,94570 & 8,65187 & 32,19597 & 0,10463 & 1,61771 \\
\hline \multirow{2}{*}{6} & 1 & 0,012769 & 2,33531 & 0,023282 & 0,99991 & & 0 & 0 & 0 \\
\hline & 2 & 4,31334 & 0 & $-0,0044634$ & 1,08837 & 8,59028 & 31,99067 & 0,10241 & 1,56865 \\
\hline \multirow{2}{*}{7} & 1 & 0,014967 & 2,30293 & 0,024792 & 1,00323 & & 0 & 0 & 0 \\
\hline & 2 & 4,77049 & 0 & $-7,33724 \mathrm{e}-5$ & 1,96739 & 14,47881 & 31,72791 & 0,12992 & 1,56088 \\
\hline \multirow{2}{*}{8} & 1 & 0,014941 & 2,30337 & 0,024790 & 1,00326 & & 0 & 0 & 0 \\
\hline & 2 & 4,77293 & 0 & $-7,24162 \mathrm{e}-5$ & 1,96988 & 14,44556 & 31,72989 & 0,12979 & 1,53080 \\
\hline \multirow{2}{*}{9} & 1 & 0,016253 & 2,31952 & 0,025285 & 1,01352 & & 0 & 0 & 0 \\
\hline & 2 & 7,13822 & 0 & $-1,46198 \mathrm{e}-5$ & 2,29440 & 20,25629 & 31,68840 & 0,15348 & 1,52332 \\
\hline \multirow{2}{*}{10} & 1 & 0,015230 & 2,30652 & 0,024742 & 1,00177 & & 0 & 0 & 0 \\
\hline & 2 & 6,29656 & 0 & $-2,05881 e-5$ & 2,20819 & 10,98614 & 32,05241 & 0,11605 & 1,53228 \\
\hline
\end{tabular}

Кроме того, преимуществом является идентификация динамических рядов измерений среднестатистической динамики роста не менее 10 учетных листьев двумя обобщенными функциями, содержащими, по крайней мере, две составляющие. Первая составляющая является трендом в виде биотехнического закона, а вторая является положительно направленным на рост листьев волновым уравнением. При этом у второго члена, показывающего среднестатистическое колебательное возмущение учетных листьев, половина амплитуды для длины и ширины учтенных листьев является биотехническим законом, а для периметра и площади учетных листьев половина амплитуды изменяется по закону экспоненциального роста.

\section{Список литературы:}

1. Пат. 2466351 Российская Федерация, МПK G 01 B 5 / 26 (2006.01). Способ измерения площади листьев у древесных растений / Мазуркин П.М., Шербакова Э.С.; заявитель и патентообладатель Поволжский.гос. технолог. ун-т. - №2011123352/28; заявл. 08.06.2011; опубл. 10.11.2012. 